\title{
openheart Real-world insight into public access defibrillator use over five years
}

\author{
Hannah Torney (D) , ${ }^{1,2}$ Olibhéar McAlister, ${ }^{1,2}$ Adam Harvey, ${ }^{2}$ Amy Kernaghan, ${ }^{1,2}$ \\ Rebecca Funston, ${ }^{2}$ Ben McCartney, ${ }^{2}$ Laura Davis, ${ }^{2}$ Raymond Bond, ${ }^{1}$ \\ David McEneaney, ${ }^{3}$ Jennifer Adgey ${ }^{4}$
}

\begin{abstract}
- Additional material is published online only. To view please visit the journal online (http://dx.doi.org/10.1136/ openhrt-2020-001251).
\end{abstract}

To cite: Torney $\mathrm{H}, \mathrm{McAlister} 0$, Harvey A, et al. Real-world insight into public access defibrillator use over five years. Open Heart 2020;7:e001251. doi:10.1136/

openhrt-2020-001251

Received 21 January 2020

Revised 24 April 2020

Accepted 29 April 2020
Check for updates

\section{(c) Author(s) (or their} employer(s)) 2020. Re-use permitted under CC BY-NC. No commercial re-use. See rights and permissions. Published by BMJ.

${ }^{1}$ Ulster University, Newtownabbey, Northern Ireland, UK

${ }^{2}$ HeartSine Technologies Ltd, Belfast, UK

${ }^{3}$ Cardiovascular Research Unit, Craigavon Area Hospital, Southern Health and Social Care Trust, Portadown, UK

${ }^{4}$ Belfast Heart Centre, Royal Victoria Hospital, Belfast, UK

Correspondence to Hannah Torney; torney-h1@ ulster.ac.uk

\section{ABSTRACT}

Background Public access defibrillators (PADs) represent unique life-saving medical devices as they may be used by untrained lay rescuers. Collecting representative clinical data on these devices can be challenging. Here, we present results from a retrospective observational cohort study, describing real-world PAD utilisation over a 5-year period.

Methods Data were collected between October 2012 and October 2017. Responders voluntarily submitted electronic data downloaded from HeartSine PADs, and patient demographics and other details using a case report form in exchange for a replacement battery and electrode pack. Results Data were collected for 977 patients (692 males, $70.8 \%$; 255 females, $26.1 \%$; 30 unknown, $3.1 \%$ ). The mean age (SD) was 59 (18) years (range <1 year to 101 years). PAD usage occurred most commonly in homes $(n=328,33.6 \%)$, followed by public places $(n=307,31.4 \%)$ and medical facilities $(n=128,13.1 \%)$. Location was unknown in $40(4.09 \%)$ events. Shocks were delivered to 354 patients. First shock success was 312 of 350 patients where it could be determined $(89.1 \%, 95 \% \mathrm{Cl} 85.4 \%$ to $92.2 \%$ ). Patients with reported response times $\leq 5 \mathrm{~min}$ were more likely to survive to hospital admission (89/296 (30.1\%) vs $40 / 250(16.0 \%), p<0.001)$. Response time was unknown for 431 events.

Conclusion This is the first study to report global PAD usage in voluntarily submitted, unselected real-world cases and demonstrates the real-world effectiveness of PADs, as confirmed by first shock success.

\section{INTRODUCTION}

Out-of-hospital cardiac arrest (OHCA) is a leading cause of mortality in the USA and Europe, accounting for 347000 to 700000 deaths per year. ${ }^{12}$ Patients with ventricular fibrillation (VF) or pulseless ventricular tachycardia (VT) can be treated by transthoracic electrical shocks using an automated external defibrillator (AED). The likelihood of successful defibrillation and survival to hospital admission for patients presenting with VF or VT decreases with time. ${ }^{34}$ Rapid defibrillation and early initiation of chest compressions improve survival. ${ }^{5-7}$ The 'Chain of Survival' emphasises the time-sensitive responder actions which may improve

\section{Key questions}

What is already known about this subject?

- Bystander automated external defibrillator (AED) use and rapid response times are associated with improved survival outcomes.

- Public awareness and willingness to use public access defibrillators (PADs) varies from region to region and the number of patients who receive a shock before the arrival of emergency medical services is often suboptimal.

What does this study add?

- This is the first analysis of data that were selfreported by the lay public and it gives a major insight into public access defibrillation.

- The high first shock success demonstrates that public access AEDs can be successfully used in non-clinical environments by lay rescuers.

- The paper presents an effective method of collecting post-market clinical follow-up data demonstrating safety and performance of PADs.

How might this impact on clinical practice?

- This study may further disseminate the importance of AED use by lay rescuers and dispel the fear that is associated with using an AED in emergency situations.

- Reassuring these rescuers of the safety and effectiveness of PADs could allow for earlier defibrillation and the potential for enhanced survival.

survival from OHCA. ${ }^{8}$ To maximise survival, it is essential to increase awareness of OHCA, adoption of CPR training and availability of public access defibrillators (PADs).

PAD programmes targeting strategic placement of AEDs improve OHCA outcomes. The introduction of PAD programmes have shown that where PADs were readily available, patients were defibrillated sooner and had improved survival. ${ }^{9-11}$ However, public awareness and willingness to use PADs varies from region to region and the number of patients who receive a shock before the arrival of emergency medical services (EMS) is often suboptimal. A study of survival following PAD implementation in Stockholm 
reported underutilisation ( $\mathrm{n}=74$ of 474 patients, $16 \%)$, but when available and used, $70 \%$ of patients survived to 1 month post-arrest. ${ }^{12}$ Similarly, Wissenberg et al reported low PAD use in the Danish Cardiac Arrest Registry, highlighting that only 241 of 19468 patients (1.4\%) received treatment with a PAD. Importantly, patients treated by a bystander had improved survival outcomes. ${ }^{13}$

PADs are designed to enable a lay rescuer to terminate a shockable arrhythmia prior to the arrival of EMS. Survival to hospital admission, cardiac function or neurological outcome are influenced by numerous factors such as EMS response time and pre-existing medical conditions, meaning this metric would not provide a clear evaluation of PAD performance. As such, clinical assessment of PADs through analysis of first shock success represents the most appropriate evaluation of their efficacy.

The objective of this analysis was to report post-market clinical assessment data describing the effectiveness of real-world PAD utilisation over a 5-year period and to highlight an approach to PAD post-market clinical follow-up that can be adopted throughout the medical device industry.

\section{METHODS}

Patient data collected from HeartSine PADs between October 2012 and October 2017 were analysed. Use of a PAD is defined as the responder turning on the device and placing electrodes on the patient to enable rhythm analysis. Following each use of the PADs, the end-user must replace the HeartSine Pad-Pak (single-use battery and electrode combination cartridge). To incentivise data collection, in return for a complete data package consisting of an Event Report Form and electronic event data downloaded from the PAD, the end-user was provided with a HeartSine Pad-Pak free of charge, allowing the PAD to be returned to service. HeartSine PADs have a sticker on the front and/or rear of the carry case instructing users to inform HeartSine via a web address if they use the PAD, and HeartSine distributors were instructed to inform users of this incentivised programme.

All HeartSine PADs use the same cardiac rhythm analysis algorithm and follow the same shock energy escalation protocol of $150 \mathrm{~J}-150 \mathrm{~J}-200 \mathrm{~J}$. In addition, all HeartSine PADs provide at least basic CPR instruction, with some models providing CPR feedback.

Data were anonymised and audited prior to data entry and analysis.

Patients or the public were not involved in the design, or conduct, or reporting, or dissemination plans of this research.

\section{Demographics}

The end-users, that is, rescuers who used the PAD, completed an Event Report Form after the OHCA. Data fields included patient age, gender and location of event, and details on survival (where known). The purpose of public access defibrillation is to provide OHCA patients with defibrillating shocks prior to their hospitalisation. For this reason, survival in this analysis is defined as a patient's admission to hospital care.

In addition, end-user information such as CPR or CPRDefibrillation training, and estimated response times were recorded. Response time was defined as the time from identification of cardiac arrest to arrival of the PAD.

\section{Electronic event data downloaded from PAD}

The end-user was asked to download the electronic event data from the PAD after each use. The electronic event data consists of an ECG (bipolar recording from the PAD electrodes) and impedance cardiogram trace, recorded through the electrode pads, with superimposed markers displaying audio prompts and key algorithm features. The ECG trace was analysed to determine cardiac rhythm and shock success. A shockable rhythm was defined as VF or VT with a rate $>180$ beats per minute. Similar to other published defibrillation studies, shock success was defined as the termination of a shockable rhythm for at least 5 s. ${ }^{14-16}$

\section{Statistical analysis}

Summary statistics were calculated for patient age and gender, location of event, user training, rescuer response time, survival outcomes, presenting arrhythmia and number of shocks delivered. Proportions were calculated for categorical data, and median and IQR were calculated where appropriate.

First shock success was determined, with 95\% CIs based on the binomial distribution. Associations between age, gender and first shock success were investigated by fitting a logistic model with first shock success as the dependent variable and age and gender as covariates. The association between first shock success and survival to admission was investigated by fitting a logistic model with survival to admission as the dependent variable and first shock success as covariate, and the analysis was adjusted for age and gender.

Pearson's $\chi^{2}$ test with Yates' continuity correction was applied to test the independence between proportions.

$\mathrm{R}$ programming language and $\mathrm{R}$ Studio were used for all analyses. A p value of $<0.05$ was considered statistically significant.

Exact age of patients was not recorded in 49 cases, and in a further 8 cases age was recorded as, for example, '60+', and these were treated as missing values. Similarly, 12 response times that were recorded qualitatively (eg, 'quickly' or 'within minutes') were not considered for analyses along with 419 unrecorded response times.

\section{RESULTS}

The 'Full Dataset' included all 977 cases. Electronic PAD downloads were available for all 977 cases. Analyses were performed on the subset of cases where response time was reported, defined as 'Response Time Recorded' and included 546 cases $(55.9 \%)$. 
Table 1 Number of events submitted from each country between October 2012 and October 2017

\section{Number of OHCAs}

\section{USA}

\begin{tabular}{lc}
\hline USA & $371(38.0 \%)$ \\
\hline Australia & $87(8.9 \%)$ \\
\hline Germany & $74(7.6 \%)$ \\
\hline Spain & $55(5.6 \%)$ \\
\hline UK & $53(5.4 \%)$ \\
\hline Singapore & $41(4.2 \%)$ \\
\hline Canada & $40(4.1 \%)$ \\
\hline Israel & $38(3.9 \%)$ \\
\hline Thailand & $36(3.7 \%)$ \\
\hline Italy & $29(3.0 \%)$ \\
\hline Poland & $29(3.0 \%)$ \\
\hline Sweden & $23(2.4 \%)$ \\
\hline France & $20(2.1 \%)$ \\
\hline Ireland & $16(1.6 \%)$ \\
\hline Philippines & $11(1.1 \%)$ \\
\hline Belgium & $6(0.6 \%)$ \\
\hline Netherlands & $5(0.5 \%)$ \\
\hline Norway & $5(0.5 \%)$ \\
\hline Colombia & $4(0.4 \%)$ \\
\hline Mexico & $4(0.4 \%)$ \\
\hline Chile & $3(0.3 \%)$ \\
\hline Costa Rica & $3(0.3 \%)$ \\
\hline Iceland & $3(0.3 \%)$ \\
\hline Republic of Korea & $3(0.3 \%)$ \\
\hline South Africa & $3(0.3 \%)$ \\
\hline Aruba & $2(0.2 \%)$ \\
\hline Austria & $1(0.1 \%)$ \\
\hline Burma & $1(0.1 \%)$ \\
\hline Cayman Islands & $1(0.1 \%)$ \\
\hline Denmark & $1(0.1 \%)$ \\
\hline Finland & $1(0.1 \%)$ \\
\hline Hong Kong & $1(0.1 \%)$ \\
\hline Malaysia & $1(0.1 \%)$ \\
\hline New Zealand & $1(0.1 \%)$ \\
\hline Switzerland & $1(0.1 \%)$ \\
\hline Otal & $4(0.4 \%)$ \\
\hline
\end{tabular}

OHCA, out-of-hospital cardiac arrest.

\section{Full dataset}

Data were collated from events in 35 countries. Country was unknown in four events (table 1). Events from the USA, Australia, Germany, Spain and UK amounted to approximately $66 \%$ of the total cases.
PADs were used in all patients: $692(70.8 \%)$ males and $255(26.1 \%)$ females. Gender was missing in $30(3.1 \%)$ cases. Female patients were typically older than the male patients (mean age (SD) 62 (20) years vs 58 (17) years, $\mathrm{p}=0.014$ ) and more commonly presented in a non-shockable rhythm $(\mathrm{n}=206,80.8 \%$, vs $\mathrm{n}=391,56.5 \%$, $\mathrm{p}<0.001)$. Events with known gender and survival were considered $(n=749)$, and of these events, male patients had a significantly higher survival to hospital admission compared with females (204 of 567 patients for whom survival was known $(36.0 \%)$ compared with 45 of 182 patients for whom survival was known $(24.7 \%), \mathrm{p}<0.05$ ) (a further two patients whose gender was not reported also survived to hospital admission). Of those patients whose gender was known and who received a shock $(n=345)$, survival to admission was similar for males compared with females (174 of 293 male patients who received a shock, (59.4\%) compared with 27 of 52 female patients who received a shock $(51.9 \%)$ ) (figure 1 ).

The mean age (SD) was 59 (18) years (range: less than 1 year to 101 years). The most frequent age of patient in this dataset was 60 years $(n=42)$. Age was missing in 57 cases ( 49 cases where age was not reported, and 8 cases where age was reported as a range and was treated as a missing value). Eight $(0.82 \%)$ patients were defined as paediatric patients, that is, less than 8 years old, as per American Heart Association (AHA) and European Resuscitation Council defibrillation guidelines. ${ }^{17}{ }^{18}$ Grouped patient ages are presented in figure 2.

The most common location of PAD usage was at home $(\mathrm{n}=328,33.6 \%)$. Location was not reported in $40(4.1 \%)$ of events. The relationship between location, response time and survival to hospital admission is reported in table 2.

Most users $(\mathrm{n}=844,86.4 \%)$ reported having either CPR or CPR-defibrillation training, and 35 (3.6\%) users reported having no training. Information on user training was not reported in $98(10.0 \%)$ of cases.

The median number of shocks a patient received was 1 (IQR 1-2), ranging from 1 to 13. The shock energy protocol for HeartSine PADs is $150 \mathrm{~J}-150 \mathrm{~J}-200 \mathrm{~J}$, with all subsequent shocks $200 \mathrm{~J}$.

There were 354 events where a shock was administered, and 350 events where first shock success could be determined. First shock success occurred in 312 events $(89.1 \%$, $95 \%$ CI $85.4 \%$ to $92.2 \%$ ). For those patients who did not receive a shock $(\mathrm{n}=623)$, the most prevalent rhythm was asystole $(n=333,53.5 \%)$. A HeartSine PAD was applied to $49(7.9 \%)$ patients who presented in sinus rhythm.

Age $(p=0.60)$ and gender $(p=0.11)$ were not associated with first shock success. The OR for gender as a predictor of shock success indicates that males are more likely to have a first shock success (OR 1.93, 95\% CI 0.81 to 4.23 ).

Where survival outcomes were known, first shock success was significantly associated with survival to admission (OR 4.60, 95\% CI 2.24 to $9.94, \mathrm{p}<0.001)$. There was a significant negative association between increasing age and survival to hospital admission $(\mathrm{p}<0.001)$, 


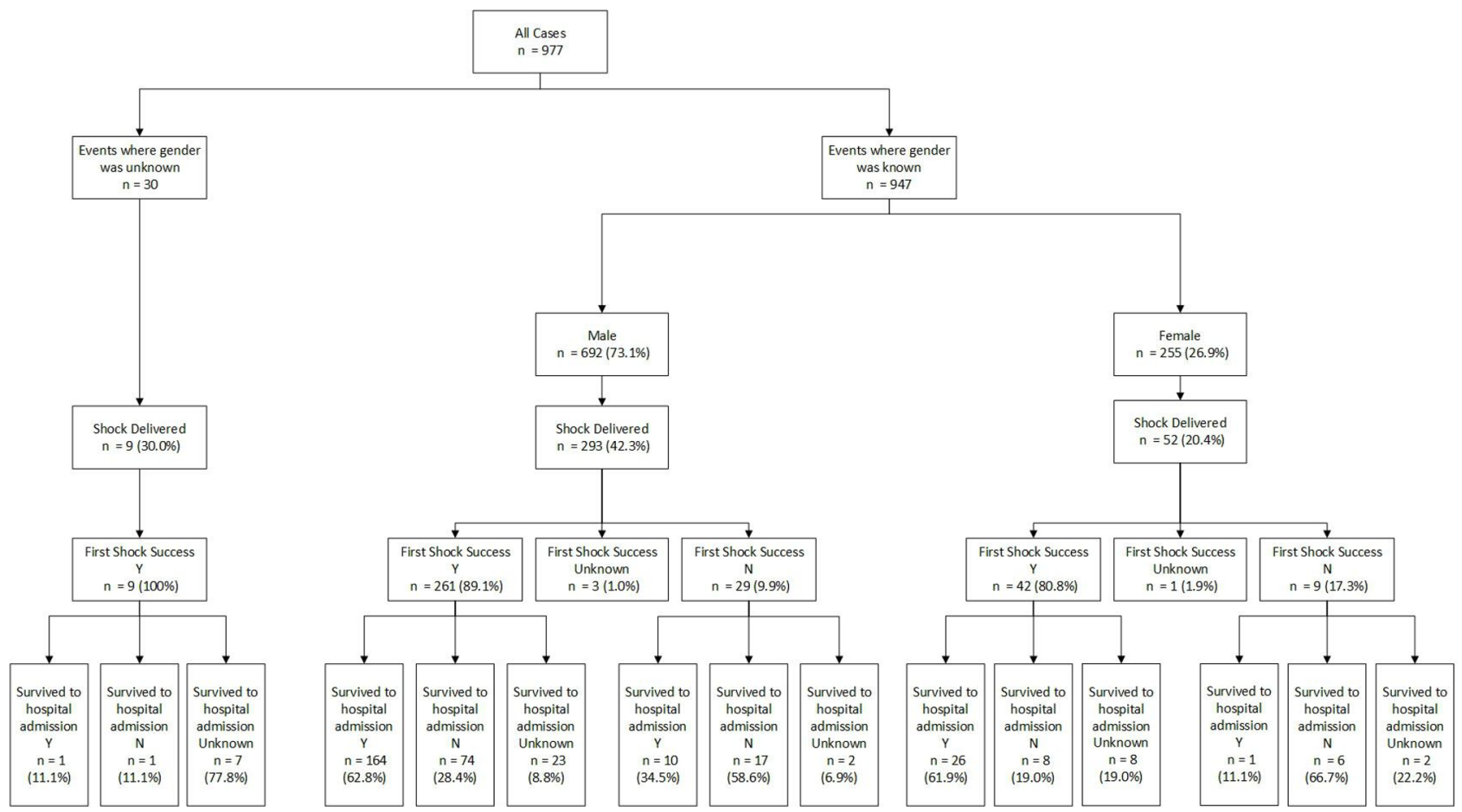

Figure 1 Flow chart depicting first shock success and survival outcomes of all known male and female patients. Gender was unknown in 30 cases, and in 9 of these patients the first shock was successful. First shock success could not be identified as in some instances the electrode pads were removed immediately after the shock or chest compressions began immediately following shock delivery.

demonstrated by the OR per 1-year increase in age as a predictor of survival to hospital admission (OR 0.98, $95 \%$ CI 0.98 to 0.99$)$. However, it is important to note that other variables such as medical history and underlying aetiology may have influenced outcome-data for which are not available. Details on medical history were provided in only $39.6 \%$ of cases.

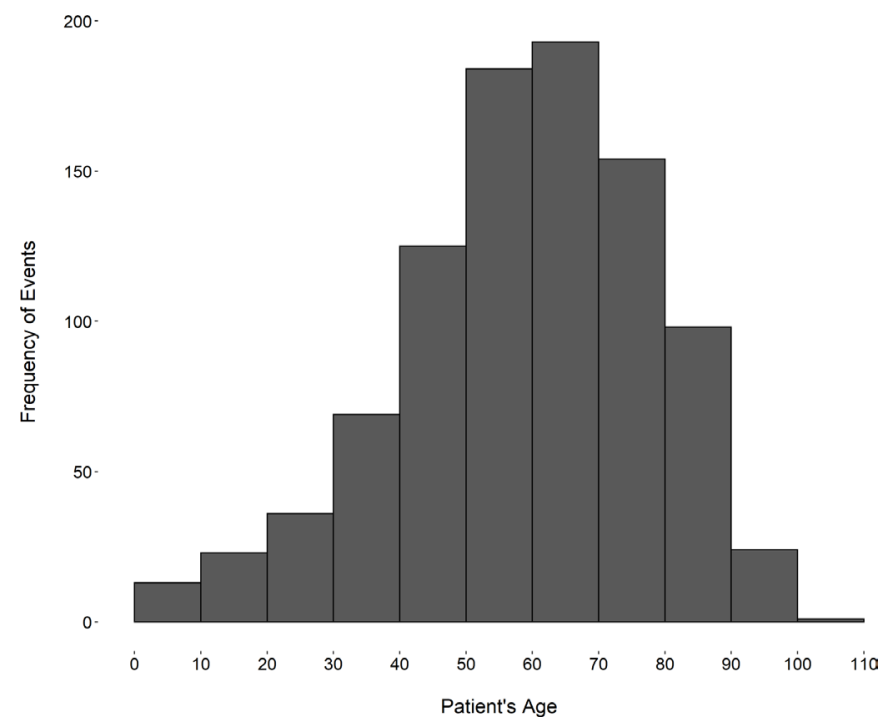

Figure 2 Histogram showing the number of events received per age band. Ages were banded in 10-year periods, that is, 0-10 years, 11-20 years etc. Age was unknown for 57 patients.
Survival to hospital admission information was unavailable for 223 events in 'Full Dataset', of which 49 (22.0\%) presented in sinus rhythm. Cardiac arrest at initial presentation could not be verified in these patients during subsequent follow-up. Of the remaining 754 events, survival to admission was confirmed for 251 (33.3\%) patients (table 2). Survival to admission for those patients who received a shock is reported in online supplementary table 1.

\section{Response time recorded}

As highlighted in the Chain of Survival, ${ }^{19}$ early recognition and treatment of OHCA is imperative to improving survival outcomes. There were a total of $546(55.9 \%)$ events in this analysis where response time was reported (table 2, figure 3).

Only observations with reported response time were included in the following analysis. The median response time (minutes) was 4 (IQR 2-6). A total of 296 (54.2\%) events had a rescuer response time of $5 \mathrm{~min}$ or less, and of these, $116(39.2 \%)$ patients presented in a shockable rhythm and $114(38.5 \%)$ of these events had at least one shock delivered. First shock success was achieved in $103(90.4 \%)$ events. Survival to hospital admission in all patients in the ' $5 \mathrm{~min}$ or less' group was $89(30.1 \%)$. Similarly, of the $250(45.8 \%)$ events with a rescuer response time of 'greater than 5 min', 77 (30.8\%) patients presented in a shockable rhythm and all of these received at least one shock. First shock success was achieved in 68 $(88.3 \%)$ events. Of the 'greater than 5 min' group, notably 
Table 2 Relationship between location, response time and percentage survival to hospital admission

\begin{tabular}{|c|c|c|c|c|c|}
\hline Location of arrest & Events (n) & $\begin{array}{l}\text { Events } \\
\text { with known } \\
\text { response } \\
\text { times (n) }\end{array}$ & $\begin{array}{l}\text { Median (IQR) response } \\
\text { time (min) }\end{array}$ & $\begin{array}{l}\text { Events with } \\
\text { known survival } \\
\text { to hospital } \\
\text { admission (n) }\end{array}$ & $\begin{array}{l}\text { Survived } \\
\text { to hospital } \\
\text { admission n (\%) }\end{array}$ \\
\hline Home & 328 & 216 & $\begin{array}{l}5 \\
(3-6)\end{array}$ & 243 & $32(13.2)$ \\
\hline Public & 307 & 171 & $\begin{array}{l}4 \\
(2-5)\end{array}$ & 254 & $89(35.0)$ \\
\hline Medical facility & 128 & 73 & $\begin{array}{l}3 \\
(2-5)\end{array}$ & 100 & $21(21.0)$ \\
\hline Sports facility & 113 & 53 & $\begin{array}{l}2.5 \\
(1-5)\end{array}$ & 96 & 75 (78.1) \\
\hline Office & 49 & 24 & $\begin{array}{l}5 \\
(3.75-9.25)\end{array}$ & 39 & $21(53.8)$ \\
\hline School/university & 12 & 8 & $\begin{array}{l}5 \\
(4.25-15)\end{array}$ & 11 & $6(54.5)$ \\
\hline Unknown & 40 & 1 & $\begin{array}{l}3 \\
(3-3)\end{array}$ & 11 & $7(63.6)$ \\
\hline Total & 977 & 546 & $\begin{array}{l}4 \\
(2-6)\end{array}$ & 754 & $251(33.3)$ \\
\hline
\end{tabular}

'Public' included public streets, parks, hotels, restaurants and recreational facilities excluding those locations reported otherwise. Medical facilities were non-hospital treatment centres, such as general practitioner offices, dental offices or residential care facilities, where the public access defibrillator is available for use by lay rescuers.

only $40(16.0 \%)$ patients survived to hospital admission. This is statistically fewer than the ' 5 min or less' group $(\mathrm{p}<0.001)$, yet the proportions of shockable rhythms and first shock successes are similar in both groups $(\mathrm{p}=0.83)$.

\section{DISCUSSION}

This analysis examined the use of PADs prior to EMS arrival and differs to other PAD studies in that the data were global real-world, unselected and not in prespecified locations. The authors did not determine where the PADs should be located. The patient demographic data collected in this study are similar to that in previous OHCA studies. ${ }^{10-24}$ The dataset contains a low proportion of paediatric patients and more reports of males suffering OHCA. Males were also more likely to survive than their female counterparts.

It was noted that female patients were typically older, and more commonly presented an initial non-shockable rhythm than male patients, in line with a recent analysis of ROC Epistry data. ${ }^{25}$ More male than female patients received a shock (42.3\% compared with $20.4 \%, \mathrm{p}<0.001$, figure 1), and their subsequent first shock success was comparable (89.1\% compared with $80.8 \%$, figure 1$)$. Of those patients with known gender and survival $(\mathrm{n}=749)$, survival to hospital admission was significantly higher in male patients $(36.0 \%$ compared with $24.7 \%, \mathrm{p}<0.05)$, a result similar to the ROC Epistry-Cardiac Arrest data analysis ${ }^{26}$ who found that men were more likely to have sustained return of spontaneous circulation (ROSC) at hospital admission, although the difference in their analysis was not significant.
The home is often reported as the most common location of OHCA, with occurrences often reported to be as high as $87 \% .^{2027} 28$ Our study identified only $33.6 \%$ of PAD uses in the home. When the relationship between location and survival to hospital admission was analysed, patients who were treated in the home were found to have the lowest rate of survival to hospital admission (13.2\%). It is worth noting that patients at home are less likely to receive bystander CPR and early defibrillation than those in public places. ${ }^{29}$ As reported in similar studies, sports facilities have the highest proportion of patients who survived to hospital admission $(\mathrm{n}=75,78.1 \%)$. Literature reports that OHCAs which occur in sports facilities are more commonly witnessed and bystander CPR is more likely to be performed..$^{30}$ Our findings also identified sports facilities as the location with the fastest rescuer response time (median 2.5 (IQR 1-5)). OHCA occurring in sports facilities often involve younger people without a history of heart disease. ${ }^{30}$ Consequently, there is often particular focus on the placement of PADs in these locations and training of sports facility staff which may explain the fast response time and high survival to hospital admission reported in our analysis.

Effectiveness of PADs in this study was confirmed by first shock success. This was determined because, although PADs remind a user to call for emergency services and instruct on how to perform effective chest compressions, there are many other confounding factors such as underlying health status which may detrimentally affect survival outcomes. Shock success of PADs is not commonly reported on, as many PAD registry studies do 


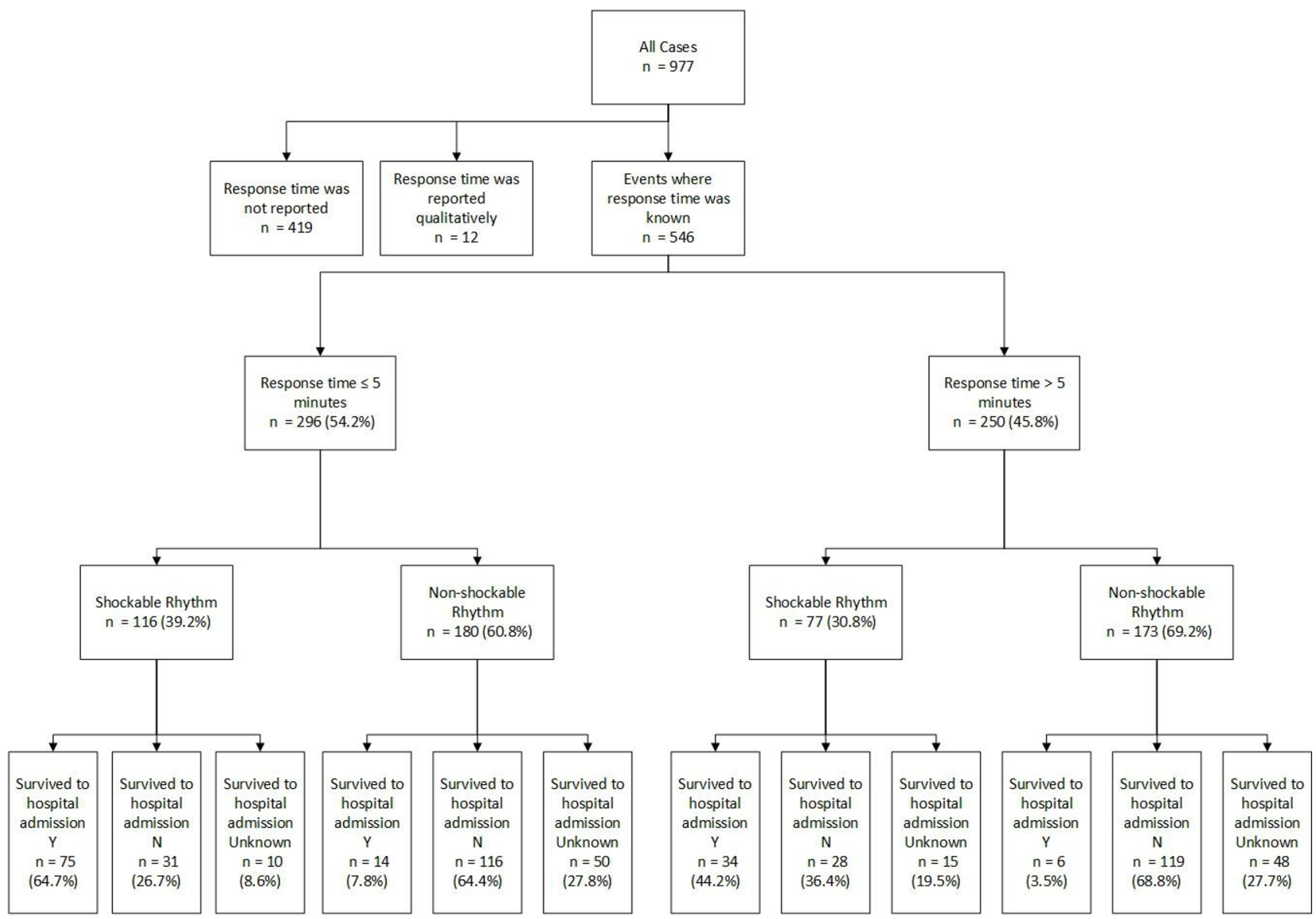

Figure 3 Flow chart depicting the proportion of patients who had a public access defibrillator applied in 5 min or less and greater than $5 \mathrm{~min}$ of out-of-hospital cardiac arrest, the proportions of shockable and non-shockable rhythms and subsequent survival outcomes.

not have access to the electronic ECG download from the AED. This study differs, as the electronic event data were available for every event. The PADs in this study use a low-energy shock escalation protocol, of $150 \mathrm{~J}-150 \mathrm{~J}-200$ J. The results demonstrated that the PADs were effective, with termination of a shockable rhythm (first shock success) occurring in $89.1 \%(n=312)$ of events. Of those whose first shock was successful in terminating the shockable rhythm, and for whom survival was known $(\mathrm{n}=274)$, $69.7 \%(\mathrm{n}=191)$ survived to hospital admission. There is often criticism of low-energy shock protocols, suggesting that low-energy defibrillation is less effective than higherenergy defibrillation. A systematic review by Morrison $e t$ al demonstrated that shock success for low-energy ( $150 \mathrm{~J})$ defibrillators is comparable with higher-energy (200 J+) equivalents. ${ }^{31}$ The results from our study demonstrated a similarly high proportion of successful first shocks compared with that previously published. ${ }^{32}$ In addition, the proportion of patients who survived to hospital admission was high for those patients who received at least one shock (ranging from $41.9 \%$ to $90.7 \%$; see online supplementary table 1 ).

There are few studies reporting the use of PADs by lay rescuers. Our study reported a high proportion of trained lay rescuers. Modern PADs are designed with simple user interfaces and audible instructions so that they could be used by anyone, regardless of training level. A survey by Brooks et al reported that $69.3 \%$ of their study population knew what an automated external defibrillator was, but only $2.1 \%$ of people would attempt to retrieve and use one in a cardiac arrest situation. ${ }^{33}$ As such, it is possible that our results contain data from trained individuals due to the higher awareness and willingness to use an AED compared with untrained individuals. The overall survival to hospital admission in our study analysis was higher than that reported in published studies assessing survival following bystander intervention, at $33.3 \%$ (table 2) compared with $21.8 \%^{13}$ as reported by Wissenberg et al. However, the improvement in survival outcomes is likely to be due to the improved availability of PADs and awareness of OHCA since the publication by Wissenberg et al.

Shorter response time is a well-known determinant of survival from OHCA. ${ }^{3-6}$ A PAD study in Denmark showed a reduction in response time from over $13 \mathrm{~min}$ to approximately $4 \min ^{34}{ }^{35}$ due to the implementation of a PAD scheme and a corresponding smartphone application scheme which alerts a responder to a nearby OHCA and the location of the nearest PAD. In addition, a study from the Danish Registry found that after these initiatives to 
improve PAD usage, 30-day survival following defibrillation in public locations increased from $8.3 \%$ in 2001/2002 to $57.5 \%$ in $2011 / 2012 .{ }^{36}$

The results of our current data collection provide a median response time of 4 (IQR 2-6) min (table 2) which is comparable with response times of other PAD programmes. ${ }^{12}$ In our study, events with response times 5 min and less had higher survival to hospital admission in comparison with those events where response times were greater than $5 \mathrm{~min}(30.1 \%$ compared with $16.0 \%$, $\mathrm{p}<0.001)$. Most notably, and to alleviate confounders, these two groups had similar proportions of patients initially presenting with a shockable rhythm $(39.2 \%$ compared with $30.8 \%$ ) (figure 3) and subsequent first shock successes (90.4\% compared with $88.3 \%$ ). In line with Weisfeldt and Becker's three-phase time model, ${ }^{37}$ these results suggest other biological factors affect survival outcome, and that lowering response time is critical for patient survival.

In 1995, the AHA recommended development and deployment of simple, inexpensive AEDs which should be placed in public locations for use by emergency rescuers and lay users. ${ }^{38}$ Since then, AEDs have become smaller, lighter and include new technologies to assist lay rescuers to perform CPR effectively. ${ }^{39}$ In addition, new technologies, such as the GoodSAM smartphone application, have been introduced to assist improvements in rescuer response times and location of PADs. ${ }^{40}$ The placement of AEDs in public places has become more common, with AEDs becoming commonplace in airports, public streets and sports facilities. Our study shows that there are still improvements to be made to reduce response times and increase survival outcomes.

Our study reports easily obtainable data which can be used to evaluate safety and performance of PADs. Safety in this study was assessed by incidence of reported hands-on shocks or misuse of the PAD. Our study did not report any safety-related events or side-effects with using a PAD and ensured the acceptability of the risks already identified. The study did not identify any misuse.

This is the first example of proactive post-market clinical assessment of PADs and is an example of how PAD assessment can be performed. Overall, the results of this study report global PAD effectiveness and reiterate the importance of easily accessible PADs and rapid initiation of the Chain of Survival.

\section{Limitations}

This study analyses data voluntarily submitted to HeartSine by end-users and does not encompass the entirety of the device use cases. We aimed to reduce any potential bias of returning only successful resuscitation attempts by incentivising the data collection, where the end-user was provided with a replacement Pad-Pak (battery and pads combination cartridge) regardless of the patient outcome. However, we do appreciate that lay responders have an unrealistic view of the success of resuscitation due to television and the media, and thus may feel that an unsuccessful resuscitation attempt was related to their actions rather than the true nature of OHCA. This could potentially lead to lack of reporting in these cases, but it should be noted that the incentive provided enables the PAD to be returned to commission without cost to the PAD owner.

There is limited information on the level of training of end-user. The Event Report Form required the enduser to self-report whether they had received CPR or CPR-D training and requirements for CPR and CPR-D training vary from region to region. As such, the level of competency displayed by 'trained' end-users is not quantified and may vary. A further limitation is in some of the reported demographic information. The Event Report Forms were completed retrospectively, which may affect the end-user's perception of their response time. In addition, it is possible that the rescuer may have estimated patient age and without access to patient files, we cannot confirm accuracy.

There is limited information on the patients' survival to hospital discharge and subsequent 30-day survival due to the end-user being responsible for the treatment only until EMS arrive. Related to this, we do not have information on sustained ROSC, as due to the nature of public access defibrillation, the PAD was removed from the patient before $20 \mathrm{~min}$ had elapsed. Due to patient confidentiality laws, it is difficult at present to collect further information.

\section{CONCLUSIONS}

This study is the first reporting global PAD use prior to the arrival of EMS and is the first representative, selfreported clinical assessment for PADs. The results of this study demonstrate the effectiveness of the PADs through a high proportion of first shock successes and highlight the relationship between rescuer response time and survival outcomes. The high proportion of events with a rescuer response time of greater than $5 \mathrm{~min}$ and the under-utilisation of PADs in the home identify areas for improvement.

Acknowledgements The authors would like to thank the lay responders who submitted the anonymised PAD use data.

Contributors HT, OMA, RF, AH and BMC contributed to the research design. AK contributed to data entry. LD audited the dataset. OMA conducted the statistical analyses. HT was the primary author for the manuscript. AH, RB, DME and JA supervised the project. All authors contributed to the interpretation of the results and reviews and drafts of the manuscript. All authors approved the submitted manuscript.

Funding This research was funded by HeartSine Technologies Ltd.

Competing interests HT and OMA are employed by HeartSine Technologies Ltd and are PhD students at Ulster University. RB is employed by Ulster University. AH, AK, RF and BMC are employed by HeartSine Technologies Ltd. LD was employed by HeartSine Technologies Ltd at the time of data collection. JA is employed by the Belfast Health and Social Care Trust and is an unpaid member of the HeartSine Clinical Advisory Board. DME is employed by the Southern Health and Social Care Trust and is an unpaid member of the HeartSine Clinical Advisory Board.

Patient consent for publication Not required.

Ethics approval This study was reviewed by the Faculty of Computing, Engineering and Built Environment Filter Committee, Ulster University, and was assigned the identification number "19.12-Torney, Hannah". 
Provenance and peer review Not commissioned; externally peer reviewed.

Data availability statement Data are available on reasonable request.

Open access This is an open access article distributed in accordance with the Creative Commons Attribution Non Commercial (CC BY-NC 4.0) license, which permits others to distribute, remix, adapt, build upon this work non-commercially, and license their derivative works on different terms, provided the original work is properly cited, appropriate credit is given, any changes made indicated, and the use is non-commercial. See: http://creativecommons.org/licenses/by-nc/4.0/.

ORCID iD

Hannah Torney http://orcid.org/0000-0003-1771-116X

\section{REFERENCES}

1 Mozaffarian D, Benjamin EJ, AS G, et al. Heart disease and stroke Statistics - 2016 update. Circulation 2015;133:e38-60.

2 Perkins GD, Handley AJ, Koster RW, et al. European Resuscitation Council Guidelines for Resuscitation 2015: Section 2. Adult basic life support and automated external defibrillation. Resuscitation 2015;95:81-99.

3 Larsen MP, Eisenberg MS, Cummins RO, et al. Predicting survival from out-of-hospital cardiac arrest: a graphic model. Ann Emerg Med 1993;22:1652-8.

4 Valenzuela TD, Roe DJ, Cretin S, et al. Estimating effectiveness of cardiac arrest interventions: a logistic regression survival model. Circulation 1997;96:3308-13.

5 Valenzuela TD, Roe DJ, Nichol G, et al. Outcomes of rapid defibrillation by security officers after cardiac arrest in casinos. $N$ Engl J Med 2000;343:1206-9.

6 Cummins RO, Eisenberg MS, Hallstrom AP, et al. Survival of outof-hospital cardiac arrest with early initiation of cardiopulmonary resuscitation. Am J Emerg Med 1985;3:114-9.

7 Pollack RA, Brown SP, Rea T, et al. Impact of bystander automated external defibrillator use on survival and functional outcomes in shockable observed public cardiac arrests. Circulation 2018;137:2104-13.

8 Cummins R, Ornato JP, Thies WH, et al. AHA Medical/Scientific Statement. Improving Survival from Sudden Cardiac Arrest: The "Chain of Survival" Concept. Circulation 1991;83:1832-47.

9 Fleischhackl R, Roessler B, Domanovits $\mathrm{H}$, et al. Results from Austria's nationwide public access defibrillation (ANPAD) programme collected over 2 years. Resuscitation 2008;77:195-200.

10 Kitamura T, Iwami T, Kawamura T, et al. Nationwide public-access defibrillation in Japan. N Engl J Med 2010;362:994-1004.

11 Weisfeldt ML, Sitlani CM, Ornato JP, et al. Survival after application of automatic external defibrillators before arrival of the emergency medical system: evaluation in the resuscitation outcomes consortium population of 21 million. J Am Coll Cardiol 2010;55:1713-20.

12 Ringh M, Jonsson M, Nordberg P, et al. Survival after public access defibrillation in Stockholm, Sweden-a striking success. Resuscitation 2015;91:1-7.

13 Wissenberg M, Lippert FK, Folke F, et al. Association of national initiatives to improve cardiac arrest management with rates of bystander intervention and patient survival after out-of-hospital cardiac arrest. JAMA 2013;310:1377-84.

14 Edelson DP, Abella BS, Kramer-Johansen J, et al. Effects of compression depth and pre-shock pauses predict defibrillation failure during cardiac arrest. Resuscitation 2006;71:137-45.

15 Whitfield R, Colquhoun M, Chamberlain D, et al. The Department of Health National Defibrillator Programme: analysis of downloads from 250 deployments of public access defibrillators. Resuscitation 2005;64:269-77.

16 Gliner BE, White RD. Electrocardiographic evaluation of defibrillation shocks delivered to out-of-hospital sudden cardiac arrest patients. Resuscitation 1999;41:133-44.

17 Atkins DL, Berger S, Duff JP, et al. Part 11: Pediatric basic life support and cardiopulmonary resuscitation quality: 2015 American Heart Association guidelines update for cardiopulmonary resuscitation and emergency cardiovascular care. Circulation 2015;132:S519-25.
18 Maconochie IK, Bingham R, Eich C, et al. European Resuscitation Council guidelines for resuscitation 2015: Section 6. Paediatric life support. Resuscitation 2015;95:223-48.

19 Nolan J, Soar J, Eikeland H. The chain of survival. Resuscitation 2006;71:270-1.

20 Bardy GH, Lee KL, Mark DB, et al. Home use of automated external defibrillators for sudden cardiac arrest. $N$ Engl J Med 2008;358:1793-804.

21 Nadkarni VM, Larkin GL, Peberdy MA, et al. First documented rhythm and clinical outcome from in-hospital cardiac arrest among children and adults. JAMA 2006;295:50-7.

22 Chugh SS, Reinier K, Balaji S, et al. Population-based analysis of sudden death in children: The Oregon Sudden Unexpected Death Study. Heart Rhythm 2009;6:1618-22.

23 Meyer L, Stubbs B, Fahrenbruch C, et al. Incidence, causes, and survival trends from cardiovascular-related sudden cardiac arrest in children and young adults 0 to 35 years of age: a 30-year review. Circulation 2012;126:1363-72.

24 Lindgren E, Ostlund O, Rubertsson S. Gender differences in outcome after out-of-hospital cardiac arrest: analysis of the LiNc trial. Circulation 2014;130:101.

25 Grunau B, Humphries K, Stenstrom R, et al. Public access defibrillators: gender-based inequities in access and application. Resuscitation 2020;150:17-22.

26 Morrison LJ, Schmicker RH, Weisfeldt ML, et al. Effect of gender on outcome of out of hospital cardiac arrest in the resuscitation outcomes consortium. Resuscitation 2016;100:76-81.

27 Hawkes C, Booth S, Ji C, et al. Epidemiology and outcomes from out-of-hospital cardiac arrests in England. Resuscitation 2017;110:133-40.

28 Capucci A, Aschieri D, Piepoli MF, et al. Tripling survival from sudden cardiac arrest via early defibrillation without traditional education in cardiopulmonary resuscitation. Circulation 2002;106:1065-70.

29 Wik L, Steen PA, Bircher NG. Quality of bystander cardiopulmonary resuscitation influences outcome after prehospital cardiac arrest. Resuscitation 1994;28:195-203.

30 Pechmajou L, Sharifzadehgan A, Bougouin W, et al. Does occurrence during sports affect sudden cardiac arrest survival? Resuscitation 2019;141:121-7.

31 Morrison LJ, Henry RM, Ku V, et al. Single-shock defibrillation success in adult cardiac arrest: a systematic review. Resuscitation 2013;84:1480-6.

32 Loma-Osorio P, Nuñez M, Aboal J, et al. The Girona Territori Cardioprotegit Project: performance evaluation of public defibrillators. Rev Esp Cardiol 2018;71:79-85.

33 Brooks B, Chan S, Lander P, et al. Public knowledge and confidence in the use of public access defibrillation. Heart 2015;101:967-71.

34 Henriksen FL, Schakow H, Larsen ML. The FirstAED global positioning system organizes a first responder team with distinct roles and ensures the possibility for early cardiopulmonary resuscitation and defibrillation. Resuscitation 2015;96:11.

35 Schakow H, Larsen ML, Henriksen FL. Emergency dispatch, FirstAED global positioning of first responders with distinct roles - a solution to reduce the response times and ensuring early defibrillation in the rural area Langeland. Scand J Trauma Resusc Emerg Med 2015;23:A4.

36 Hansen SM, Hansen CM, Folke F, et al. Bystander defibrillation for out-of-hospital cardiac arrest in public vs residential locations. JAMA Cardiol 2017;2:507-14.

37 Weisfeldt ML, Becker LB. Resuscitation after cardiac arrest: a 3-phase time-sensitive model. JAMA 2002;288:3035-8.

38 Weisfeldt ML, Kerber RE, McGoldrick RP, et al. Public access defibrillation. A statement for healthcare professionals from the American Heart Association Task Force on automatic external defibrillation. Circulation 1995;92:2763.

39 Weisfeldt ML, Pollack RA. Public access defibrillation: is this making any difference? Controversial issues in resuscitation from cardiac arrest. Card Electrophysiol Clin 2017;9:551-7.

40 Smith CM, Wilson $\mathrm{MH}$, Ghorbangholi A, et al. The use of trained volunteers in the response to out-of-hospital cardiac arrest-the GoodSAM experience. Resuscitation 2017;121:123-6. 